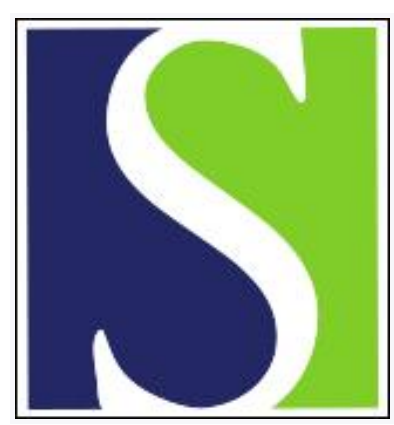

Scand J Work Environ Health 2006;32(3):185-189

https://doi.org/10.5271/sjweh.997

Issue date: 30 Jun 2006

Cancer incidence among farmers exposed to lindane while sheep dipping

by Rafnsson $\mathrm{V}$

Affiliation: Department of Preventive Medicine, University of Iceland, Neshagi 16, 107 Reykjavik, Iceland. vilraf@hi.is

Refers to the following text of the Journal: 1995;21(4):296-300

The following article refers to this text: 2016;42(2):144-152

Key terms: cancer incidence; cancer registry; exposure; farmer; gamma-hexachlorocyclohexane; lindane; lip cancer; sheep dipping

This article in PubMed: www.ncbi.nlm.nih.gov/pubmed/16804620

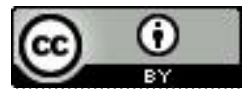




\title{
Cancer incidence among farmers exposed to lindane while sheep dipping
}

\author{
by Vilhjalmur Rafnsson, $M D^{1}$
}

\begin{abstract}
Rafnsson V. Cancer incidence among farmers exposed to lindane while sheep dipping. Scand J Work Environ Health 2006;32(3):185-189.
\end{abstract}

\begin{abstract}
Objectives The objective of this study was to determine whether site-specific cancer incidence among farmers exposed to the insecticide lindane ( $\gamma$-hexachlorocyclohexane) while dipping sheep differs from that of the general population in Iceland.

Methods Cohorts of 7882 men and 429 women, who, according to records on sheep dipping, were sheep owners, were followed from 1962 to 2003 in the Cancer Registry for cancer incidence. The observed number of cancers was compared with expected values, calculated on the basis of person-years of risk and cancer incidence in the general population of Iceland.

Results For men the standardized incidence ratio (SIR) for all cancer sites was 0.79 , with a $95 \%$ confidence interval $(95 \% \mathrm{CI})$ of $0.76-0.83$. For both the men and the women a significantly increased risk for lip cancer was found, with SIR of 1.50 (95\% CI 1.08-2.04) and 9.09 (95\% CI 1.02-32.82), respectively. The SIR for several cancer sites were lower than unity for both the men and women. Examples were cancers of the colon, rectum, pancreas, stomach, lungs, kidney, bladder, and brain and nervous system.

Conclusions The decreased risk of most cancers among these sheep farmers agrees with findings reported previously among farmers from other countries, as well as in Iceland. Cancer of the lip was the only cancer type in significant excess among both genders, and the stomach cancer rates were near unity, but, in previous studies on Icelandic farmers, an increase had been found for stomach cancer. The site-specific cancer incidence for sheep-dipping farmers did not differ substantially from that of the general population.
\end{abstract}

Key terms $\gamma$-hexachlorocyclohexane; cancer registry; lip cancer.

Although farmers have an increased risk for certain cancers, studies in many countries indicate that farmers tend to have low mortality from all causes, heart disease, and all cancers, mainly due to low mortality for esophagus, colon, bladder, and lung cancer as compared with the general population and nonfarmers $(1,2)$. The specific cancers often found with increased frequency among farmers include leukemia, Hodgkin's disease, nonHodgkin's lymphoma, multiple myeloma and tumors of the lip, stomach, skin, prostate, brain and connective tissue, as reported in two recent meta-analyses $(1,2)$. In both studies, it was suggested that the results were due to agricultural chemical exposures, viruses, or other factors related to agricultural activity $(1,2)$, while the authors interpreted the informative value of the meta-analysis as limited concerning potential carcinogenic exposure in agriculture, due to the heterogeneity of the exposures by type of farming, geographic area, time period, and other factors $(1,2)$.

In previous studies on Icelandic farmers, nonstatistically significant excesses were found for Hodgkin's disease, cancer of the lip, skin and nervous system, nonHodgkin's lymphoma, and leukemia $(3,4)$. In these register-based studies, there was a lack of information on the type of farming pursued by the individual farmers, their livestock and their exposure to pesticides, fertilizers, machine exhaust and the like, and how long they had been farming (4). A later study among Icelandic pesticide users indicated that certain insecticides, particularly organophosphorus compounds and carbamates, were used in the horticultural sector (5), while lindane ( $\gamma$-hexachlorocyclohexane) was used in sheep dip (6). Because of the polar maritime climate in Iceland, it was assumed that the use of herbicides and pesticides was not as intense as in warmer climates. After the publication of the initial farmers' studies, however, we learned about the extensive use of lindane among sheep farmers $(3,4)$. Technical grade hexachlorocyclohexane $(\mathrm{HCH})$ is a mixture of mainly five isomers, the approximate weights are $\alpha-\mathrm{HCH} 60 \%$ to $70 \%, \beta-\mathrm{HCH} 7 \%$ to $10 \%, \gamma$-HCH (lindane) $14 \%$ to $15 \%, \delta$ - $\mathrm{HCH} 7 \%, \varepsilon-\mathrm{HCH}$ $1 \%$ to $2 \%$, and others $1 \%$ to $2 \%$. The $\gamma$-isomer is called

1 Department of Preventive Medicine, University of Iceland, Reykjavik, Iceland.

Reprint requests to: Dr V Rafnsson, Department of Preventive Medicine, University of Iceland, Neshagi 16, 107 Reykjavik, Iceland. [E-mail: vilraf@hi.is] 
lindane, and it is the active insecticide component of $\mathrm{HCH}$. Technical grade $\mathrm{HCH}$ and $\alpha-\mathrm{HCH}$ are considered carcinogenic in animals, with limited evidence of carcinogenetic activities having been found for $\beta-\mathrm{HCH}$ and $\gamma$-HCH in animals (7). The evidence for the carcinogenicity of $\mathrm{HCH}$ in humans is inadequate (7). The sites induced in animals by the different forms of $\mathrm{HCH}$ include liver, lymphoreticular, and thyroid (7).

With access to official records on sheep dipping in Iceland, and in light of the information already presented, a study of the cancer incidence among sheep farmers in Iceland in a retrospective cohort study seemed pertinent.

\section{Material and methods}

In this study, the primary source of data was paper records, extending over the period 1962-1980, on sheep dipping from the Icelandic Veterinary Services. Annual dipping of sheep to combat ectoparasites, mainly sheep scab mite, Psoroptes ovis, has been compulsory in Iceland since $1914(6,8)$. A law adopted in 1959 reduced the requirement to one compulsory dip every other year. The obligation to dip the sheep fell on the sheep owner (the farmer), and special inspectors ensured the correct mixing of the dip, the general conditions under which it was performed, and that all sheep were dipped $(8,9)$. The farmers in Iceland dip their sheep inside during the winter, after bringing their herds in from highland pastures; no contractors were ever engaged in sheep dipping. The preparation Gamatox ${ }^{\circledR}$ (Cooper McDougall and Robertson Ltd, Berkhamsted, England) was used in sheep dip from 1947 onwards (10), and it was the only insecticide used for this purpose until the entire practice of dipping was replaced around 1980 by an annual prophylactic injection of ivermectin and related medicine against ectoparasites. At the beginning, Gamatox ${ }^{\circledR}$ contained technical-grade $\mathrm{HCH}$, that is, a mixture of isomers, which was replaced with $\gamma$ - $\mathrm{HCH}$ (lindane) in the mid-1970s. Organophosphates were never used in sheep dip in Iceland although they have been widely used in the United Kingdom (11). Advice to farmers on how to perform the dipping and how to mix the dip from a concentrate of Gamatox ${ }^{\circledR}$ is given on the reverse side of the records on sheep dipping. Noninfested sheep are to be totally immersed in the dip for 1 minute, and the head of the animal should be dipped briefly three times. Infested animals should be immersed for 3 minutes, and their heads dipped five times. After a herd is dipped, the inside of the sheepshed is to be scrubbed with the remainder of the dip, with a broom, for example. No advice is given concerning personal protection, and dip- ping is hard and dirty work, known to involve skin contamination, as has also been recognized elsewhere (11).

Records of sheep dipping are kept by the inspectors, and a special form is signed as verification. The records contain information on the time of the dip, the name, address, community, and gender of the sheep owner. The name, gender, and home address of the sheep owner were used to look up his or her personal identification number in community-based paper files of residents, which are old versions of the National Registry. All residents of Iceland are included in the National Registry under a unique personal identification number, which everyone receives at birth (a 10-digit number that includes the day, month, and year of birth). A total of 204 persons on the record could not be identified and were thus not included in the study. A total of $7882 \mathrm{men}$ and 429 women were entered into the study.

The personal identification number of each person was used in record linkage to the National Registry to confirm the date of death or date of emigration. This procedure made it possible to ascertain the vital status of the total cohort. A second record linkage was made to the Icelandic Cancer Registry, which is a nationwide registry of cancer cases compiled and maintained since 1955. Over $94 \%$ of these cases have been histologically verified (12).

Person-years were calculated for each person, commencing in the first year a name appeared on the records and ending with the person's date of death or emigration, or at the end of 2003, the last year of the followup period, whichever came first (13). The number of expected cancers was calculated on the basis of personyears for each 5-year age category and the cancer incidence rates for the male and female population of Iceland obtained from the Icelandic Cancer Registry. The ratio between observed and expected numbers of cancers, the standardized incidence ratio (SIR), was calculated along with the $95 \%$ confidence interval $(95 \% \mathrm{CI})$, on the assumption of a Poisson distribution and the use of Byar's approximation (13).

The National Bioethics Committee and the Data Protection Commission approved the study.

\section{Results}

Altogether 7882 men were followed in the cohort, and their total number of person-years was 213 685. The women were 429 in number, with 10439 person-years. Table 1 and table 2 show the observed and expected number of cancer cases, the standardized incidence ratios, and the $95 \%$ confidence intervals for all cancers and for cancers of selected sites among the men and women, respectively. During the follow-up period, 
Table 1. Observed $(0)$ and expected $(E)$ number of neoplasms standardized incidence ratio (SIR), and 95\% confidence interval $(95 \% \mathrm{Cl})$ for 7882 male sheep farmers (213 685 person-years) followed from 1962 to 2003.

\begin{tabular}{lrrrc}
\hline Cancer sites $^{\text {a }}$ & \multicolumn{1}{c}{$\mathrm{E}$} & $\mathrm{SIR}$ & $95 \% \mathrm{Cl}$ \\
\hline All sites (140-205) & 1818 & 2296.23 & 0.79 & $0.76-0.83$ \\
Lip (140) & 41 & 27.33 & 1.50 & $1.08-2.04$ \\
Mouth (143-144) & 8 & 9.06 & 0.88 & $0.38-1.74$ \\
Pharynx (145-149) & 9 & 10.50 & 0.86 & $0.39-1.63$ \\
Esophagus (150) & 32 & 46.93 & 0.68 & $0.47-0.96$ \\
Stomach (151) & 227 & 235.96 & 0.96 & $0.84-1.10$ \\
Colon (153) & 104 & 179.74 & 0.58 & $0.47-0.70$ \\
Rectum (154) & 41 & 66.96 & 0.61 & $0.44-0.83$ \\
Liver and gallbladder (155) & 26 & 36.53 & 0.71 & $0.46-1.04$ \\
Pancreas (157) & 50 & 80.45 & 0.62 & $0.46-0.82$ \\
Nose, nasal cavities, sinuses (160) & 10 & 8.86 & 1.13 & $0.54-2.08$ \\
Larynx (161) & 11 & 23.87 & 0.46 & $0.23-0.82$ \\
Trachea, bronchus and lung (162) & 137 & 252.10 & 0.54 & $0.46-0.64$ \\
Breast (170) & 7 & 6.27 & 1.12 & $0.45-2.30$ \\
Prostate (177) & 541 & 586.89 & 0.92 & $0.85-1.00$ \\
Testis (178) & 7 & 6.41 & 1.09 & $0.44-2.25$ \\
Kidney (180) & 80 & 115.93 & 0.69 & $0.55-0.86$ \\
Bladder (181) & 95 & 155.54 & 0.61 & $0.49-0.75$ \\
Skin melanoma (190) & 22 & 24.42 & 0.90 & $0.56-1.36$ \\
Other skin (191) & 69 & 73.71 & 0.94 & $0.73-1.18$ \\
Brain/nervous system (193) & 43 & 49.84 & 0.86 & $0.62-1.16$ \\
Thyroid (194) & 28 & 35.55 & 0.79 & $0.52-1.14$ \\
Bone (196) & 2 & 4.94 & 0.40 & $0.05-1.46$ \\
Soft tissue (197) & 12 & 11.60 & 1.03 & $0.53-1.81$ \\
Unspecified sites (199) & 41 & 51.00 & 0.80 & $0.58-1.09$ \\
Hodgkin's disease (201) & 9 & 9.68 & 0.93 & $0.42-1.77$ \\
Non-Hodgkin's lymphoma (200-202) & 45 & 49.78 & 0.90 & $0.66-1.21$ \\
Multiple myeloma (203) & 33 & 32.44 & 1.02 & $0.70-1.43$ \\
Leukemia (204) & 56 & 54.68 & 1.02 & $0.77-1.33$ \\
Other neoplasms & 32 & 49.26 & 0.65 & $0.44-0.92$ \\
& & & & \\
\hline
\end{tabular}

a Code of the International Classification of Diseases, seventh revision, in parentheses.

1818 cancers were diagnosed in the whole cohort of men versus 2296.2 expected; thus there was a substantial deficit. The standardized incidence ratios for several cancer sites were lower than unity. Cancer of the lip was the only cancer site in significant excess. Among the women, the observed number of all cancers was 77 versus 106.9 expected. The standardized incidence ratio was low for all of the cancers and for most of the cancers sites, and, as among the men, there was an excess
Table 2. Observed $(0)$ and expected (E) number of neoplasms, standardized incidence ratio (SIR), and 95\% confidence interval $(95 \% \mathrm{Cl})$ for 429 female sheep farmers (10 439 person-years) followed from 1962 to 2003

\begin{tabular}{|c|c|c|c|c|}
\hline Cancer sites $^{\mathrm{a}}$ & 0 & $\mathrm{E}$ & SIR & $95 \% \mathrm{Cl}$ \\
\hline All sites (140-205) & 77 & 106.94 & 0.72 & $0.57-0.90$ \\
\hline Lip (140) & 2 & 0.22 & 9.09 & $1.02-32.8$ \\
\hline Stomach (151) & 4 & 7.35 & 0.54 & $0.15-1.3$ \\
\hline Colon (153) & 8 & 9.56 & 0.84 & $0.36-1.6$ \\
\hline Liver and gallbladder (155) & 1 & 2.09 & 0.48 & $0.01-2.66$ \\
\hline Pancreas (157) & 1 & 3.94 & 0.25 & $0.00-1.41$ \\
\hline Trachea, bronchus and lung (162) & 8 & 10.37 & 0.77 & $0.33-1.52$ \\
\hline Breast (170) & 13 & 23.13 & 0.56 & $0.30-0.9$ \\
\hline Cervix uteri (171) & 1 & 2.45 & 0.41 & $0.01-2.27$ \\
\hline Corpus uteri (172) & 3 & 4.90 & 0.61 & $0.12-1.79$ \\
\hline Ovary (175) & 4 & 5.42 & 0.74 & $0.20-1.8$ \\
\hline Kidney (180) & 4 & 3.91 & 1.02 & $0.28-2.62$ \\
\hline Bladder (181) & 1 & 3.28 & 0.30 & $0.00-1.70$ \\
\hline Skin melanoma (190) & 2 & 1.72 & 1.16 & $0.13-4.20$ \\
\hline Other skin (191) & 2 & 3.27 & 0.61 & $0.07-2.21$ \\
\hline Brain/nervous system (193) & 1 & 2.81 & 0.36 & $0.00-2.98$ \\
\hline Thyroid (194) & 4 & 3.36 & 1.19 & $0.32-3.05$ \\
\hline Soft tissue (197) & 2 & 0.46 & 4.35 & $0.49-15.70$ \\
\hline Unspecified sites (199) & 4 & 3.88 & 1.03 & $0.28-2.64$ \\
\hline Non-Hodgkin’s lymphoma (200-202) & 2 & 1.92 & 1.04 & $0.12-3.76$ \\
\hline Multiple myeloma (203) & 2 & 1.49 & 1.34 & $0.15-4.85$ \\
\hline Leukemia (204) & 5 & 2.33 & 2.15 & $0.69-5.0$ \\
\hline Other neoplasms & 3 & 9.08 & 0.33 & $0.07-0.9$ \\
\hline
\end{tabular}

a Code of the International Classification of Diseases, seventh revision, in parentheses.

of cancer of the lip, although the excess was based on only two cases. The categories with only one cancer case are shown for the sake of completeness.

Table 3 shows the observed and expected number of all cancers and cancer of the lip with a breakdown by birth cohort among the men. The standardized incidence ratios for all cancers were similar in the different birth cohorts. However, the younger the group, the higher the standardized incidence ratio for lip cancer. The

Table 3. Observed $(0)$ and expected $(\mathrm{E})$ number, standardized incidence ratio (SIR), and 95\% confidence interval $(95 \% \mathrm{CI})$ of all cancer and lip cancer according to the birth cohorts of the men.

\begin{tabular}{|c|c|c|c|c|c|c|c|c|c|c|}
\hline \multirow[t]{2}{*}{ Age group } & \multirow{2}{*}{$\begin{array}{l}\text { Number } \\
\text { of men }\end{array}$} & \multirow{2}{*}{$\begin{array}{l}\text { Person- } \\
\text { years }\end{array}$} & \multicolumn{4}{|c|}{ All cancer } & \multicolumn{4}{|c|}{ Lip cancer } \\
\hline & & & 0 & $E$ & SIR & $95 \% \mathrm{Cl}$ & 0 & $E$ & SIR & $95 \% \mathrm{Cl}$ \\
\hline Born before 1901 & 1047 & 14685 & 272 & 329.22 & 0.83 & $0.73-0.93$ & 6 & 7.24 & 0.83 & $0.30-1.80$ \\
\hline Born 1901 to 1910 & 1284 & 28148 & 420 & 526.54 & 0.80 & $0.72-0.88$ & 11 & 9.31 & 1.18 & $0.59-2.11$ \\
\hline Born 1911 to 1920 & 1499 & 42884 & 511 & 659.12 & 0.78 & $0.71-0.85$ & 12 & 7.34 & 1.63 & $0.84-2.86$ \\
\hline Born 1921 to 1930 & 1523 & 49837 & 377 & 503.44 & 0.75 & $0.68-0.83$ & 9 & 2.58 & 3.49 & $1.59-6.62$ \\
\hline Born after 1930 & 2530 & 78132 & 238 & 277.91 & 0.86 & $0.75-0.97$ & 3 & 0.86 & 3.49 & $0.70-0.19$ \\
\hline
\end{tabular}


standardized incidence ratio for other cancer sites (including stomach cancer) had a pattern similar to that for all cancer, the standardized incidence ratios were evenly distributed by birth cohort.

\section{Discussion}

This study showed low incidence rates for all cancers and most of the cancer sites among both the men and the women and an excess of lip cancer.

The cancer pattern of these cohorts of men and women agrees with what has been presented in the two previously mentioned meta-analyses on farmers $(1,2)$ and two recent studies of female farmers and female farm residents $(14,15)$. The increased risk of lip cancer has been attributed to farmers' outdoor work and their resulting exposure to ultraviolet light. The present small cohort of female farmers also had an excess of lip cancer, and the present study is the first to show the increase of this cancer site among female farmers. The incidence of lip cancer has been studied extensively among Norwegian farmers (16). That study found that exposure to immunosuppressive mycotoxins may be a factor in explaining the increase of lip cancer among farmers, along with exposure to ultra violet rays from the sun (16).

Stomach cancer among Icelandic farmers has also attracted special interest (17). Previous Icelandic studies showed an excess of stomach cancer among farmers $(18,19)$, which was not confirmed in later studies (3, 4 ), and in the present study the standardized incidence ratio for stomach cancer was near unity.

The use of lindane in an agricultural setting has the most frequently been related to non-Hodgkin's lymphoma (20) and brain cancer (21) in epidemiologic studies. The present study results did not show an excess of these cancers. Nor was there an excess of cancer of the sites frequently found in animal studies (ie, liver, lymphoreticular, and thyroid). The standardized incidence ratios for cancers of lymphatic and hematopoietic tissue, prostate cancer, and stomach cancer were near unity in contrast to the results for many other cancer sites, for which the standardized incidence ratios were significantly lower than unity.

Comparing farmers with the general population has well known limitations and invites the healthy worker effect (13). The healthy worker effect is primarily of concern in mortality studies and appears to be less significant for cancer incidence, but it may nevertheless mask real effects (13). In light of the low cancer rates in general, the interpretation of standardized incidence ratios for cancer sites that are near unity is difficult because of this masking. Surveys on smoking among farmers and the general population in Iceland are available from 1985 to 1988 , and they indicate that farmers smoke less than nonfarmers (22). This lower level of smoking may contribute to the lower incidence of smoking-related cancers such as cancer of the trachea, bronchus and lung, larynx, bladder, and pancreas. The same pattern of cancer incidence among farmers was found in a study from the other Nordic countries (23).

The present study focuses on sheep farmers, who were engaged in dipping their sheep and thus exposed to lindane; however, no other information was available on their farm activity (ie, whether they had other types of livestock as well, or how long they had been farming). Information on lifestyle factors among these sheep farmers, other than that on smoking, is limited, but work-related exposures may include exposures that started in childhood.

The strength of the study lies in the use of the comprehensive population registries in Iceland, particularly the Icelandic Cancer Registry. The universal use of personal identification numbers made record linkage possible and, therefore, ascertained vital and emigration status for all of the cohort members and secured complete identification of cancers in the nationwide Cancer Registry. The cancer incidence rates for the population were also obtained from the Cancer Registry; thus the source of information on cancers was the same for the cohort and the comparison material. Over $94 \%$ of the cancers reported to the Cancer Registry have histologically confirmed diagnoses (12).

In conclusion, the decreased risk of most cancers among these sheep farmers agreed with findings reported previously for farmers in general in Iceland and with results from farmers' studies in other countries. Cancer of the lip was the only cancer type in significant excess among both genders, and stomach cancer rates were near unity, but in previous studies on Icelandic farmers an increase had been found for stomach cancer. The sitespecific cancer incidence for sheep-dipping farmers did not differ substantially from that of the general population.

\section{Acknowledgments}

Thanks go to Helgi Sigvaldason for his statistical advice and assistance.

\section{References}

1. Blair A, Hoar Zahm S, Pearce NE, Heineman EF, Fraumeni JF Jr. Clues to cancer etiology from studies of farmers [review]. Scand J Work Environ Health. 1992;18:209-15. 
2. Acquavella J, Olsen G, Cole P, Ireland B, Kaneene J, Schuman S, et al. Cancer among farmers: a meta-analysis. Ann Epidemiol. 1998;8:64-74.

3. Rafnsson V, Gunnarsdottir, H. Mortality of farmers in Iceland. Int J Epidemiol. 1989;18:146-51.

4. Gunnarsdottir H, Rafnsson V. Cancer incidence among Icelandic farmers 1977-1987. Scand J Soc Med. 1991;19:170-3.

5. Zhong Y, Rafnsson V. Cancer incidence among Icelandic pesticide users. Int J Epidemiol. 1996;25:1117-24.

6. Lög um sauðfjárbaðanir [Sheep dipping Act of 1959, Pub. L. No. 23, Iceland (April 27, 1959)].

7. International Agency for research on Cancer (IARC). Overall evaluations of carcinogenicity: an updating of IARC monographs volumes 1 to 42. Lyon: IARC; 1987. IARC Monographs on Evaluation of Carcinogenic Risks to Humans, supplement 7, p. 220-2.

8. Ricther SH, Eydal M, Sigurdsson S. Ectoparasites on sheep in Iceland. Iceland Agr Sci. 1997;11:91-8.

9. Palsson PA. Um maurakláða á sauðfé. [On ectoparasites in sheep]. Freyr. 1964;60:310-8.

10. Palsson PA. Færilús og fjárkláđi. [The sheep ked and the sheep scab mite]. Freyr. 1969;65:115-8.

11. Rees H. Exposure to sheep dip and the incidence of acute symptoms in a group of Welsh farmers. Occup Environ Med. 1996;53:258-63.

12. Tulinius H, Ragnarsson J. Cancer incidence in Iceland 19551984. Reykjavik: Cancer Society and Director General of Health; 1987.

13. Breslow NE, Day NE. Statistical methods in cancer research, vol ii-the design and analysis of cohort studies. Lyon: International Agency for Research on Cancer, 1987.

14. Wiklund K, Dich J. Cancer risk among female farmers in Sweden. Cancer Causes Control. 1994;5:449-57.
15. Wang Y, Lewis-Michl E, Hwang SA, Fitzgerald EF, Stark AD. Cancer incidence among a cohort of female farm residents in New York state. Arch Environ Health. 2002;57:5617.

16. Nordby KC, Andersen A, Kristensen P. Incidence of lip cancer in male Norwegian agricultural population. Cancer Causes Control. 2004;15:619-26.

17. Dungal N. The special problem of stomach cancer in Iceland: with particular reference to dietary factors. JAMA. 1961;178:789-98.

18. Sigurjonsson J. Occupational variations in mortality from gastric cancer in relation to dietary differences. $\mathrm{Br} \mathrm{J}$ Cancer. 1967;21:651-656.

19. Tulinius H, Sigvaldason H. Cancer incidence and occupations in an area of low air pollution. In: Peto R, Scheiderman M, editors. Banbury report 9: qualification of occupational cancer. New York (NY): Cold Spring Harbor Laboratory; 1981. p 523-41.

20. Blair A, Cantor KP, Zahm SH. Non-Hodgkin's lymphoma and agricultural use of the insecticide lindane. Am J Ind Med. 1998;33:82-7.

21. Davis JR, Brownson RC, Garcia R, Bentz JB, Turner A Family pesticide use and childhood brain cancer. Arch Environ Contam Toxicol. 1993;24:87-92.

22. Ragnarsson J, Blöndal T. Reykingavenjur 1985-1988 [Smoking habits 1985-1988]. Heilbrigðisskýrslur. Fylgirit 1989 nr 2. Reykjavík: Landlæknisembættið; 1989.

23. Andersen A, Barlow L, England A, Kjærheim K, Lynge E, Pukkala E. Work-related cancer in the Nordic countries. Scand J Work Environ Health. 1999;25(suppl 2):1-116.

Received for publication: 18 October 2005 